\title{
Technetium-99m hexamethyl propylene amine oxime granulocyte scintigraphy in Crohn's disease: diagnostic and clinical relevance
}

\author{
G Sciarretta, A Furno, M Mazzoni, C Basile, P Malaguti
}

\begin{abstract}
Scintigraphy with autologous granulocytes labelled by technetium-99m hexamethyl, propylene amine oxime ( ${ }^{99 m}$ Tc-HMPAO) was performed in 103 Crohn's disease patients and 52 healthy controls. In 31 patients endoscopic and histologic activity was compared with scan activity index. In the 98 patients with a positive scan, the extent of Crohn's disease, assessed by scintigraphy, was compared with that evaluated by small bowel $x$ ray or colonoscopy with biopsies. In 48 patients, Crohn's disease activity index, activity index, simple index, erythrocyte sedimentation rate, C-reactive protein were correlated with the scan results. In 16 patients the five parameters and scan were repeated after treatment with methylprednisolone (10 cases), enteral nutrition (3), and 5-acetylsalicylic acid (3). The results showed that ${ }^{99 m}$ Tc-HMPAO granulocyte scan had a $95 \%$ sensitivity and $100 \%$ specificity to detect active inflammation; it correctly showed an abscess or a fistula in all the $\mathbf{2 4}$ cases found. The correlation between histological inflammatory activity and scan activity index was highly significant $(r=0.85 ; p<0.01)$, less significant $(r=0.65 ; p<0.01)$ between endoscopy and scan activity index. The evaluation for the extent of Crohn's disease by scan was completely correct in the small bowel $(100 \%)$ and $\mathbf{9 3} \%$ correct in the large bowel. No correlation was seen between the three clinical activity parameters and scanning; in more than $80 \%$ of the cases in remission on the basis of a clinical or laboratory index, scintigraphy remained positive. Medical treatment was effective on the clinical indices but not on the active inflammation in the ileum, whereas it led to a negative scan in 5/11 cases in the large intestine. Scintigraphy with ${ }^{99 m}$ Tc-HMPAO granulocyte plays an important part in Crohn's disease for the diagnosis of complications, for activity and assessment of the extent, and for the treatment results evaluation.

(Gut 1993; 34: 1364-1369)
\end{abstract}

Crohn's disease is characterised by a chronic recurrent pattern that often leads to complications that require an operation. Besides the difficulties entailed in making an exact diagnosis, ${ }^{1}$ there is some uncertainty about the correct definition of the disease activity, a decisive basis for the choice of treatment, and the assessment of results. Various clinical ${ }^{2-4}$ and laboratory ${ }^{5-8}$ indices have been suggested for this purpose, but often with contrasting results because of the subjective and aspecific nature of the parameters considered for their construction. ${ }^{9}$ The role of endoscopy for the evaluation of the severity and the response to steroid treatment of Crohn's disease has recently been emphasised. ${ }^{1011}$

Abdominal scintigraphy with leucocytes or pure granulocytes labelled with 111-indium has been judged capable of showing the site, extent, and degree of inflammation in inflammatory bowel diseases. ${ }^{1213}$ The measurement of faecal excretion of 111-indium has been shown to be a reliable quantitative index of intestinal inflammation $^{14}$ 15; the setting up of a semiquantitative scintigraphic activity grading, obtained from scintigraphic images ${ }^{1213}$ and well correlated with faecal excretion of 111 -indium, ${ }^{12}{ }^{13}$ has simplified the clinical use of this method.

In this study, scintigraphy using pure fractions of autologous granulocytes labelled with technetium-99m hexamethyl propylene amine oxime (99mTc-HMPAO) was performed in 103 patients with Crohn's disease. The aim was to check whether this tracer is able to show the presence of active inflammation, the extent, and any complications such as abscesses or fistulas. In a subgroup of 31 patients, the scan activity index was compared blindly with the inflammatory activity assessed by histology and with the severity of the endoscopic signs. In all cases with a positive scan, the extent of Crohn's disease, assessed by scan, was compared with that seen on small bowel $x$ ray or colonoscopy. In 48 cases the scan activity index was correlated with three clinical parameters: Crohn's disease activity index. of Best et $a l,{ }^{2}$ activity index of Van Hees et al, ${ }^{3}$ simple index of Harvey and Bradshaw, ${ }^{4}$ and with the erythrocyte sedimentation rate and C-reactive protein, and in 16 of these it was repeated after medical treatment to assess its usefulness in the clinical follow up of Crohn's disease.

\section{Methods}

PATIENTS

Of the 355 patients examined by granulocyte scintigraphy from January 1988, because they were suspected to be suffering from inflammatory bowel disease, 103 had Crohn's disease, 54 men and 49 women, aged 15-78 ( $x=38 \cdot 3 \mathrm{y})$. Crohn's disease was found in the small intestine in 58 (56 ileum, 2 ileum and jejunum), in the large intestine in 14 , and in both in $31 ; 38$ had had surgery from one month to 30 years previously $(x=5.7 y)$ and suffered from Crohn's disease relapse. Diagnosis in unresected cases within the small bowel was based on small intestine double 
constrast enema in 26 , on ileoscopy with biopsies in three, and on histological examination of surgical specimens in three. In the cases in the large bowel and in those where recurrence occurred after surgery diagnosis was based on colonoscopy or ileocolonoscopy with biopsies. When abscess or fistula complications were suspected, the final diagnosis was based on computed tomography, repeated ultrasound scans, specific $x$ ray examinations, and, in three cases, on surgical exploration; in five cases, a cutaneous or anal fistula was present.

The control group consisted of 52 subjects, 22 men and 30 women with a mean age of 62 years, with hip prosthesis, not receiving non-steroid anti-inflammatory drugs and free from intestinal disease; they had granulocyte scintigraphy for suspected septic loosening of the graft.

Comparison between the endoscopic-histological picture and scan was possible in a subgroup of 31 patients where colonoscopy with biopsies had been performed within one week of the granulocyte scintigraphy: this was to avoid possible interference by drug treatment on the scan results. The endoscopic signs considered as expressions of activity and severity were: oedema-erythema, aphthoid erosions, and deep ulcers. At microscopic examination a subjective evaluation of granulocyte infiltrate increase was given as: absent, slight, moderate, and severe. These endoscopic-histological data were given for the intestinal segments that had been adequately examined. The intestine was divided as follows: distal ileum, caecum/ascending colon, transverse colon, descending colon, sigmoid/ rectum, and surgical anastomoses. The segments studied were classified, on the basis of the endoscopic pattern, in three groups: (1) oedema of mucosa without active lesions; (2) moderate activity with erythema or aphthoid erosions, or both; (3) severe activity with deep ulcers. Normal segments, group 0 , were considered as controls. Correlations were made between the endoscopic, histologic, and scintigraphic data and the diagnostic sensitivity and specificity of granulocyte scintigraphy were assessed.

The extent of Crohn's disease was assessed in the 98 patients with a positive scan, by a small bowel $x$ ray in the 84 cases where it was found in the small bowel, by pancolonoscopy in the 45 patients where the colon was affected. The small bowel was divided into three segments: distal ileal loop; an ileal tract; a jejunum tract. ${ }^{16}$ In the colon, a segment was considered affected when histological examination showed Crohn's disease activity, even if only slight. Scan evaluations were made blindly by the nuclear medicine physician, unaware of the results from the other examinations. The extent of Crohn's disease assessed by scan was compared, in each case, with that made by $x$ ray for the small bowel, and by colonoscopy for the large bowel.

In $48 / 103$ patients it was possible to calculate the three activity parameters, Crohn's disease activity index, activity index, simple index and two laboratory parameters, erythrocyte sedimentation rate and C-reactive protein, at the same time as when the granulocyte scintigraphy was performed. In this subgroup Crohn's disease was found in the small intestine in 21 , in the ileum and large intestine in 18, and in the large intestine only in nine; 18 cases had Crohn's disease relapse after resection. Seven cases were newly diagnosed and therefore untreated; three were already having treatment with salozopyrin, nine with 5-acetylsalicylic acid (5-ASA), and 10 with low doses of steroids; treatment had been stopped for at least one month in 19 cases.

In $16 / 48$ patients, the five parameters and granulocyte scintigraphy were rechecked, in 10 after treatment with methyl-prednisolone $(1 \mathrm{mg} /$ $\mathrm{kg} /$ body/wt per day for 3-4 weeks gradually decreasing the dose for a further 6-8 weeks) plus 5-ASA ( $3 \mathrm{~g} /$ day up to the control) after 6-12 months ( $x=8$ months); in three after total enteral nutrition for 2-3 months plus 5-ASA $3 \mathrm{~g} /$ day up to the control after three months; in three patients, two in remission and one in activity, treated with 5-ASA $3 \mathrm{~g} /$ day, after 6,8 , and 16 months respectively. In the group treated with methyl-prednisolone, a statistical assessment (Wilcoxon's rank test) was made of the variation in the parameters considered.

\section{RADIONUCLIDE PROCEDURES}

The scintigraphic study was performed after obtaining the informed consent according to the Declaration of Helsinki. Autologous granulocytes labelled with ${ }^{99 m}$ Tc-HMPAO (CeretecAmersham Int) were used. The cellular fraction was obtained by centrifugation on double density gradient modifying the technique already described by Ferrante and Thong. ${ }^{17}$

In brief, $90 \mathrm{ml}$ of blood was collected from the patient and made non-coagulable by adding 16 $\mathrm{ml}$ of acid citrate dextrose (formula A); after a first sedimentation with the dilution with $10 \mathrm{ml}$ of hydroxyethyl starch (Hespan), the supranatant plasma, rich in leucocytes and platelets, was centrifuged at $300 \mathrm{~g}$ for 10 minutes; the cellular pellet thus obtained was delicately resuspended in $5 \mathrm{ml}$ of plasma cell free and placed on a double density gradient produced by diluting with different quantities of plasma $(0 \cdot 1$ and $1 \mathrm{ml})$ $2 \mathrm{ml}$ of Ficoll-Hypaque (MPRM-Flow Lab). After another centrifugation at $300 \mathrm{~g}$ for 10 minutes, the neutrophils were recovered at the interface between the two density gradients, washed in plasma, and then incubated for 10 minutes at room temperature in $1 \mathrm{ml}$ of plasma and $1 \mathrm{ml}$ of ${ }^{99 \mathrm{~m}} \mathrm{Tc}$-HMPAO (740-1110 MBq). After labelling, the cells were washed again in plasma, recovered by centrifuging ( $400 \mathrm{~g}$ for 5 minutes), resuspended in $5 \mathrm{ml}$ of plasma, and promptly reinjected into the patient.

The dose given varied, according to the labelling yield, between 370 and $555 \mathrm{MBq}$. More than $95 \%$ of the cells present in the final suspension were neutrophil granulocytes, the remainder being erythrocytes, monocytes, and some eosinophils; there were no lymphocytes. Cell vitality, assessed by trypan blue staining, was always at least $99 \%$.

The scans were performed with the whole body technique after 30 minutes, 2-2.5 hours, and, when an abscess or fistula was suspected, also after 24 hours. The early examination represents an in vivo quality control of the preparation and is able to show at this stage the presence of 
inflammation in the upper respiratory tract that may give rise to false positive results in a later scan. ${ }^{18}$

\section{SCAN ACTIVITY INDEX}

Our scan activity index was obtained by modifying slightly the scintigraphic grading used by Saverymuttu et al,,$^{13}$ maintaining unchanged the granulocyte uptake index of 0 to 3: Grade $0=$ no uptake; Grade 1=uptake<bone marrow; Grade $2=$ uptake <liver; Grade 3=uptake >liver, and the colonic division into: caecum/ascending colon, transverse colon, descending colon, sigmoid-rectum colon; small bowel was divided into: distal ileal loop, an ileal tract, a jejunum tract. ${ }^{16}$ Where up to half of a large intestine segment was affected, the uptake grade was multiplied by 0.5 to assess more exactly the extent of the Crohn's disease. Scan activity index was the sum of the uptake degree, evaluated on the two hour image, for each segment that had a positive scan.

\section{Results}

Granulocyte scintigraphy gave positive results in 98 of the 103 patients with Crohn's disease, by visualising at least one part of the intestine. In five ileal cases in clinical remission granulocyte scintigraphy did not show any intestinal activity. Granulocyte scintigraphy was negative in all 52 control subjects; the diagnostic sensitivity was therefore $95 \%$ and specificity $100 \%$.

Granulocyte scintigraphy showed a total of 24 complications, 10 abscesses and 14 fistulas. Scintigraphic diagnosis is based on the presence of a focal accumulation of labelled cells unchanged in the 24 hour examination for abscesses (Fig 1A and B). In the presence of fistulas, anomalous stabs were shown (Fig 2). Nine complications, six abscesses and three fistulas, were not clinically suspected before granulocyte scintigraphy was performed, and so scanning was performed for the following examinations. In all cases, these were subsequently confirmed. There was no false positive result in our cases. In the 31 patients with Crohn's disease examined with endoscopy, histology, and granulocyte scintigraphy, the 88 suitable intestinal segments were divided as follows: surgical anastomoses, 8; distal ileum, 18; caecum/ ascending colon, 15; transverse colon, 17; descending colon, 14; sigmoid/rectum, 16.

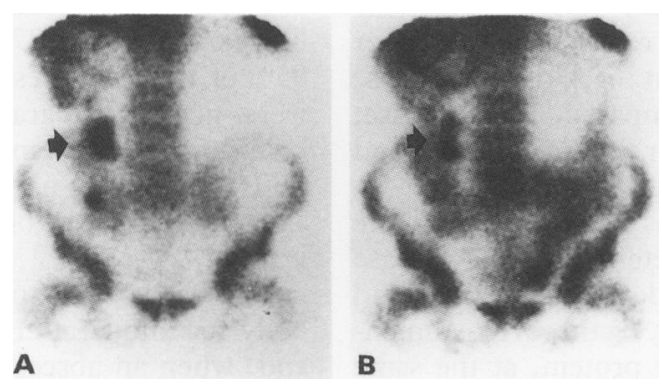

Figure 1: Recurrent Crohn's disease in a patient who has had a resection: focal uptake (arrow) at two hours $(A)$ unchanged after 24 hours $(B)$, suggesting an abscess complication.

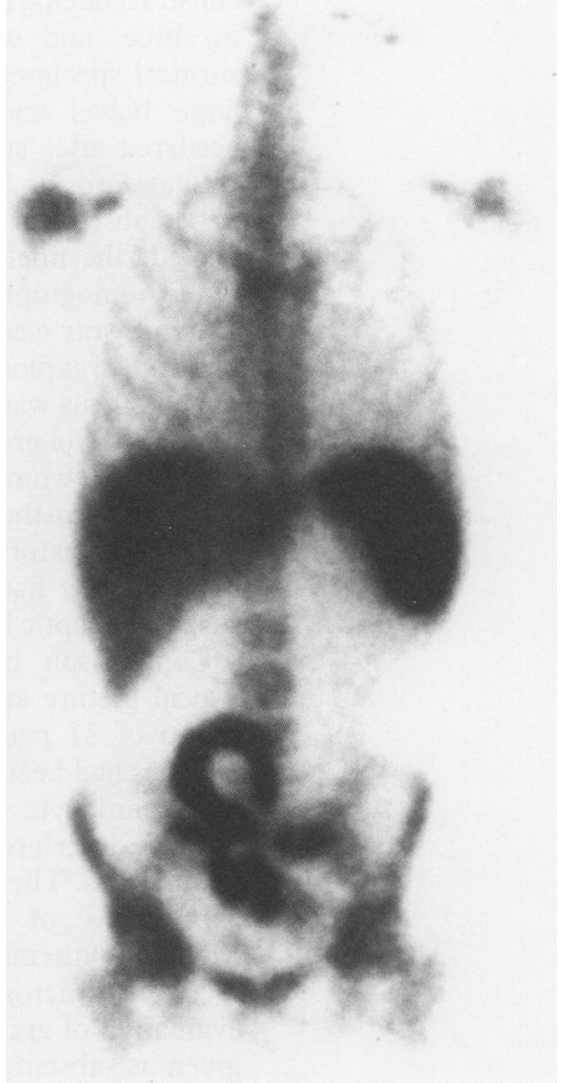

Figure 2: Evidence of fistulous communication between ileum and sigmoid colon in a patient with active Crohn's disease.

Table I gives the scan results, correlated with endoscopic and histologic data. The linear correlation of scan activity index with endoscopic severity and activity was significant $(r=0.65$; $\mathrm{p}<0.01$ ); the correlation between the degree of histological activity and the scan activity index value was highly significant, with $r=0.85$, $\mathrm{p}<0.01$. From an analysis of these data, granulocyte scintigraphy has shown a diagnostic sensitivity and specificity for active inflammation of $95 \%$ and $100 \%$.

The extent of Crohn's disease assessed by granulocyte scintigraphy showed exactly in $84 / 84$ in the small bowel compared with radiological examination; for the 45 found in the colon, granulocyte scintigraphy evaluation was correct in 42 (93\%): in the three other cases, with slight activity, the extent was underestimated by granulocyte scintigraphy.

In the 48 patients in whom Crohn's disease activity index, activity index, simple index, erythrocyte sedimentation rate, C-reactive protein, and total scan activity index were cal-

TABLE I Scan results correlated with the endoscopic and histologic data of 88 intestinal segments in 31 patients with Crohn's disease

\begin{tabular}{|c|c|c|c|c|c|c|c|c|}
\hline & \multirow[b]{2}{*}{0} & \multicolumn{3}{|c|}{ Endoscopy } & \multirow[b]{2}{*}{0} & \multicolumn{3}{|c|}{ Histology } \\
\hline & & $l$ & 2 & 3 & & 1 & 2 & 3 \\
\hline $\begin{array}{r}\text { Scan activity index } \\
1 \\
1 \\
2 \\
3\end{array}$ & $\begin{array}{l}10 \\
- \\
-\end{array}$ & $\begin{array}{l}3 \\
\overline{1} \\
3\end{array}$ & $\begin{array}{r}1 \\
20 \\
12 \\
-\end{array}$ & $\begin{array}{r}\overline{8} \\
13 \\
17\end{array}$ & $\begin{array}{r}10 \\
- \\
- \\
-\end{array}$ & $\begin{array}{r}4 \\
24 \\
4 \\
-\end{array}$ & $\begin{array}{r}- \\
20 \\
1\end{array}$ & $\begin{array}{r}- \\
4 \\
2 \\
19\end{array}$ \\
\hline
\end{tabular}

Scan activity index $v$ endoscopy: $\mathrm{r}=0.65 ; \mathrm{p}<0.01$; scan activity index $v$ histology: $\mathrm{r}=0 \cdot 85 ; \mathrm{p}<0.01$. 
TABLE II Correlations of the five activity parameters with scan activity index in 48 patients with Crohn's disease

\begin{tabular}{|c|c|c|c|c|}
\hline \multirow[b]{2}{*}{ Parameters } & \multicolumn{2}{|c|}{$\begin{array}{l}\text { All patients } \\
(n=48)\end{array}$} & \multicolumn{2}{|c|}{$\begin{array}{l}\text { Small bowel } \\
(n=2 l)\end{array}$} \\
\hline & $r$ & $p$ & $r$ & $p$ \\
\hline Crohn's disease activity index & $0 \cdot 22$ & NS & 0.43 & $\star$ \\
\hline Activity index & $0 \cdot 23$ & NS & 0.47 & * \\
\hline Simple index & $0 \cdot 21$ & NS & 0.43 & $\star$ \\
\hline Erythrocyte sedimentation rate & 0.29 & $\star$ & $0 \cdot 18$ & NS \\
\hline $\mathrm{C}$-reactive protein & $0 \cdot 35$ & $\star \star$ & $0 \cdot 33$ & NS \\
\hline
\end{tabular}

${ }^{\star} \mathrm{p}<0 \cdot 05 ;{ }^{\star \star} \mathrm{p}<0.01$

culated, correlations were made between each of the five parameters and scan activity index for the whole group and for the subgroups made on the basis of the site of the Crohn's disease: the three clinical parameters Crohn's disease activity index, activity index, and simple index correlate with scan activity index only for the forms of the disease found in the small intestine and not for

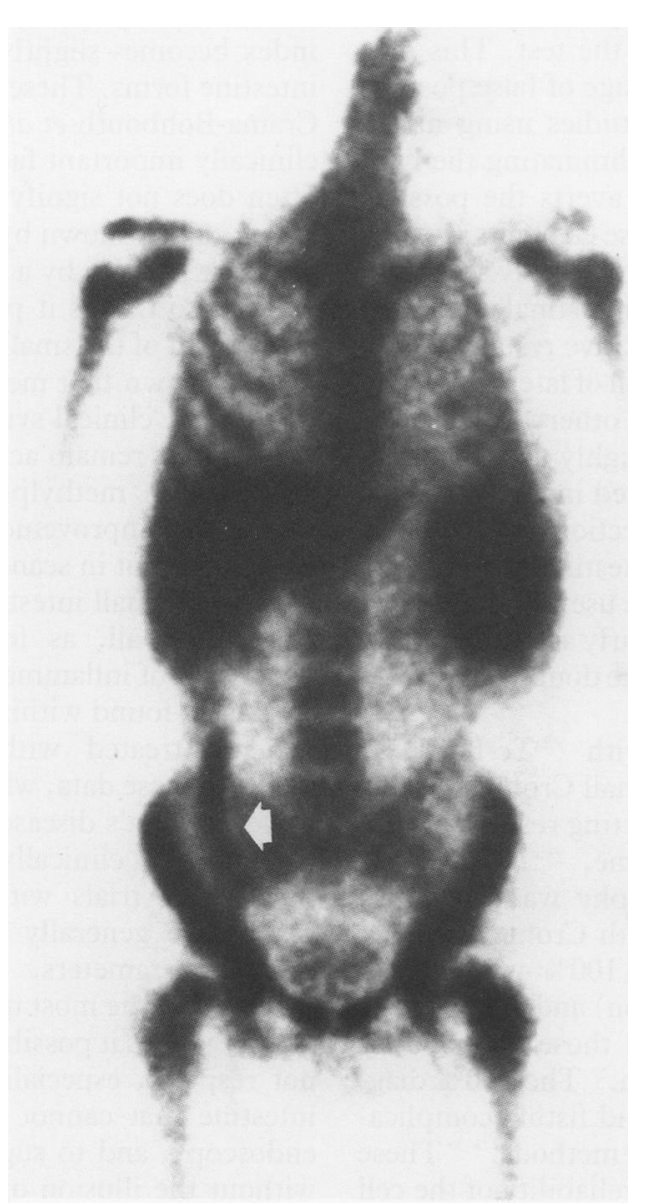

Figure 3: Increased granulocyte uptake in a patient with ileal Crohn's disease (arrow) in clinical remission.

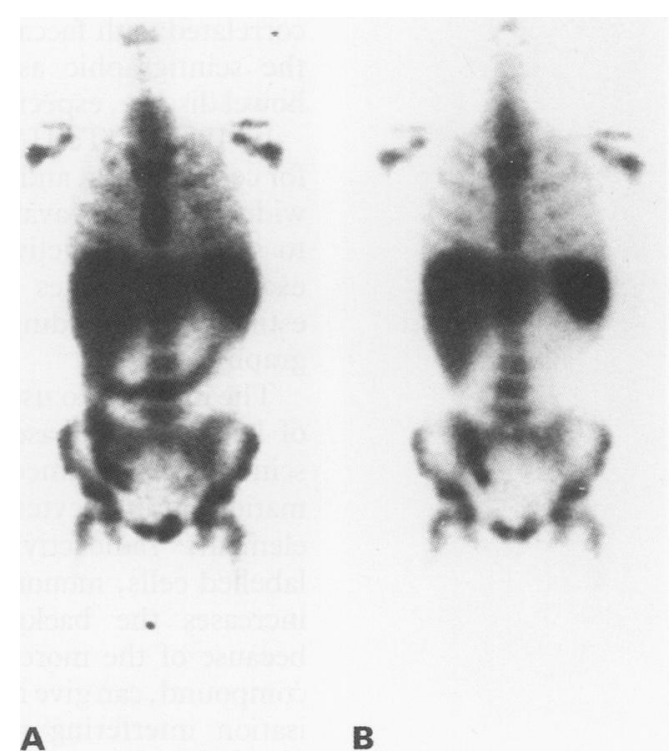

Figure 4: Crohn's disease affecting the ileum and colon: before $(A)$ and after $(B)$ steroid treatment. Disappearance of inflammatory activity only from the colon.

the other groups, while erythrocyte sedimentation rate and C-reactive protein correlate with scan activity index for the entire group (Table II). In a high proportion of cases in remission for one parameter (more than $80 \%$ ), granulocyte scintigraphy is positive with no substantial difference in scan activity index compared with the cases clinically active (Fig 3 ).

Analysing the variations in the five parameters and scan activity index in the patients treated with methylprednisolone, a significant decrease of Crohn's disease activity index, activity index, simple index, erythrocyte sedimentation rate values is seen, while there is no significant reduction in C-reactive protein and scan activity index (Table IV). If scan activity index is divided into its two components, for the small and large intestine, it can be seen that granulocyte scintigraphy becomes negative in $2 / 8$ cases where the colon was affected (Fig 4). In the six patients who had a different treatment similar results can be seen, with scan activity index becoming negative in only three cases where the colon was affected.

\section{Discussion}

Indium 111-leucocyte scintigraphy has been shown to have a high diagnostic accuracy in inflammatory bowel disease ${ }^{1319}$ and the faecal

TABLE III Changes in activity parameters and scan activity index after methylprednisolone treatment in 10 patients

\begin{tabular}{|c|c|c|c|c|c|c|c|c|}
\hline $\begin{array}{l}\text { Steroid } \\
\text { treatment }\end{array}$ & $\begin{array}{l}\text { Crohn's } \\
\text { disease } \\
\text { activity index }\end{array}$ & Activity index & Simple index & $\begin{array}{l}\text { Erythrocyte } \\
\text { sedimentation } \\
\text { rate }\end{array}$ & $\begin{array}{l}C \text {-reactive } \\
\text { protein }\end{array}$ & $\begin{array}{l}\text { Scan activity } \\
\text { index }\end{array}$ & $\begin{array}{l}\text { Small } \\
\text { bowel-scan } \\
\text { activity index }\end{array}$ & $\begin{array}{l}\text { Large } \\
\text { bowel-scan } \\
\text { activity index }\end{array}$ \\
\hline Before & $\begin{array}{l}238 \\
(166-324)\end{array}$ & $\begin{array}{l}205 \\
(120-294)\end{array}$ & $\begin{array}{l}7 \cdot 1 \\
(4-10) \\
\star\end{array}$ & $\begin{array}{l}59 \\
(15-94)\end{array}$ & $\begin{array}{l}3 \cdot 8 \\
(0 \cdot 5-7 \cdot 9) \\
\text { NS }\end{array}$ & $\begin{array}{l}5 \cdot 9 \\
(2-13) \\
\text { NS }\end{array}$ & $\begin{array}{l}2 \cdot 6 \\
(2-3) \\
\text { NS }\end{array}$ & $\begin{array}{l}4 \cdot 4 \\
(2-10) \\
\text { NS }\end{array}$ \\
\hline After & $\begin{array}{l}167 \\
(10-284)\end{array}$ & $\begin{array}{l}169 \\
(76-255)\end{array}$ & $\begin{array}{l}5 \cdot 3 \\
(1-11)\end{array}$ & $\begin{array}{l}29 \\
(8-59)\end{array}$ & $\begin{array}{l}2 \cdot 7 \\
(0 \cdot 4-8 \cdot 5)\end{array}$ & $\begin{array}{l}4 \cdot 2 \\
(1-7)\end{array}$ & $\begin{array}{l}2 \cdot 2 \\
(1-3 \cdot 5)\end{array}$ & $\begin{array}{l}2 \cdot 8 \\
(0-5)\end{array}$ \\
\hline
\end{tabular}

${ }^{\star} \mathrm{p}<0.05$ (Wilcoxon's rank test). 
excretion of the labelled cells is well correlated with Crohn's disease activity. ${ }^{1420}$ The use of a scintigraphic index based on an assessment of the intensity and extent of the inflammation, well correlated with faecal excretion, ${ }^{13}$ has simplified the scintigraphic assessment of inflammatory bowel disease, especially Crohn's disease.

In $1986^{21}{ }^{99} \mathrm{~m}$ Tc-HMPAO was made available for cell labelling, and has the advantages of being widely and easily available, exposing the patients to smaller radioactive loads, requiring shorter examination times and, not to be underestimated, providing a better quality scintigraphy image. ${ }^{22}$

The decision to use pure granulocytes instead of leucocytes is based on the fact that, as the scintigraphy is aimed at showing active inflammation, granulocytes represent its fundamental element; radioactivity bound to the other labelled cells, mononucleates and erythrocytes, increases the background radioactivity and, because of the more rapid elution of the radio compound, can give rise to early intestinal visualisation interfering negatively with the image quality and the accuracy of the test. This may account for the high percentage of false positive results reported in recent studies using mixed leucocytes. ${ }^{23}$ Furthermore, eliminating the lymphocytes from the test also averts the possible risk of genetic damage to these elements. ${ }^{24}$

Our method is based on a total body scan after 30 minutes to show any extraintestinal inflammation that might give false positive results, and to permit a correct interpretation of later scans with regard to extent, which can otherwise be overestimated in patients with highly active inflammation and with an accelerated intestinal transit (for example, after ileum resection). The physiological elimination in the intestine of the ${ }^{99 m} \mathrm{Tc}$ HMPAO metabolites may be useful for a correct interpretation of the site of early activity in those cases where there may be some doubt between an ileal and a sigmoid loop.

Mixed leucocyte scan with ${ }^{99 m}$ Tc-HMPAO labelling has been used in small Crohn's disease series sometimes with conflicting results. ${ }^{162526} \mathrm{In}$ this study, for the first time, ${ }^{99 \mathrm{~m}} \mathrm{Tc}-\mathrm{HMPAO}$ 'pure' granulocyte scintigraphy was used in a large number of patients with Crohn's disease; $95 \%$ diagnostic sensitivity $(100 \%$ without the five cases in clinical remission) and $100 \%$ specificity are better results than those obtained by 111 -indium granulocyte scan. ${ }^{27}$ The $100 \%$ diagnostic accuracy of abscess and fistula complications was not seen with other methods. ${ }^{28-30}$ These data show the accuracy and reliability of the cell preparation method, labelling, and scintigraphic technique used by us. Obviously granulocyte scintigraphy cannot be used to diagnose Crohn's disease, which is based on other methods, but it can show the active inflammation that is part of Crohn's disease.

In cases where the intestinal segments were studied endoscopically and histologically, a high correlation was seen between scan activity index and the degree of histological inflammatory activity, with values of sensitivity and specificity higher than those obtained with ${ }^{99 m}$ Tc-HMPAO leucocytes. ${ }^{26}$ The endoscopic activity and severity of lesions also showed a good correlation with scan activity index. Granulocyte scintigraphy assessment of the extent of Crohn's disease was very accurate, with only three cases underestimated, probably because of the low activity and the interference with bladder image. Total scan activity index can thus give a precise evaluation of activity and severity in Crohn's disease. Another important aspect is the measurement of the clinical activity of Crohn's disease. The various clinical and laboratory parameters have been shown to be unreliable and difficult to standardise because of the subjective nature of some of the parameters used. ${ }^{915}$ In Crohn's disease an assessment of activity is important for therapeutic decisions and to evaluate the efficacy of the treatments used. The endoscopic index, ${ }^{10}$ not easy to carry out, cannot be used in all cases as Crohn's disease is often localised in the small intestine. Our data show that the scintigraphic parameter is not correlated with the clinical parameters but is, however only slightly, with C-reactive protein and erythrocyte sedimentation rate; the correlation with Crohn's disease activity index, activity index, and simple index becomes slightly significant for the small intestine forms. These data reflect those seen by Crama-Bohbouth et $a l,{ }^{20}$ and are the result of a clinically important fact: clinical remission very often does not signify inflammatory remission, which can be shown by endoscopy with biopsies or, more simply, by a granulocyte scintigraphy, which also makes it possible to give an overall assessment of the small intestine.

It is known that methylprednisolone is effective for the clinical symptoms, ${ }^{31}$ but the inflammation may remain active. ${ }^{1132}$ In the 10 patients treated with methylprednisolone, there was a significant improvement in the clinical parameters but not in scan activity index: inflammation in the small intestine, in particular, did not respond at all, as found by Olaison et el. . $^{32}$ Remission of inflammation was only recorded in $5 / 11$ cases found within the colon, including the patients treated with enteral nutrition and 5-ASA. These data, which show a poor response of ileal Crohn's disease to traditional treatment, are important clinically and for the assessment of therapeutic trials with new drugs where the results are generally assessed on the basis of clinical parameters, Crohn's disease activity index being the most usual. ${ }^{31}$ Granulocyte scintigraphy makes it possible to identify cases that do not respond, especially those within the small intestine that cannot always be explored with endoscopy, and to suggest different treatments without the illusion of a clinical remission that may hide a persistent active inflammation. ${ }^{33}$

As far as granulocyte specific monoclonal antibody labelled by ${ }^{99 \mathrm{~m}} \mathrm{Tc}$ is concerned for "in vivo' labelling, the diagnostic accuracy is lower and clinical experience too small. ${ }^{34}{ }^{35}$ In conclusion, ${ }^{99 m}$ Tc-HMPAO granulocyte scintigraphy seems to be better than other scintigraphic methods in the study of Crohn's disease, is clinically useful because of its ability to show abscess and fistular complications, provides an assessment of the active inflammation and the extent of the disease (particularly useful where the small intestine is affected) and allows a true evaluation of inflammatory activity even 
during clinical remission and in response to treatment.

Part of this paper has been published in abstract form at the EANM Congress of Lisboa, August, 1992.

Lennard-Jones JE. Classification of inflammatory bowe disease. Scand F Gastroenterol 1989; 24 (suppl 170): $2-6$

2 Best WR, Becktel JM, Singleton JW. Rederived values of the eight coefficients of the Crohn's disease activity index (CDAI). Gastroenterology 1979; 77: 843-6.

3 Van Hees PAM, Van Elteren PH, Van Lier HJJ, Van Tongeren JHM. An index of inflammatory activity in patients with Crohn's disease. Gut 1980; 21 : 279-86.

4 Harvey RF, Bradshaw JM. A simple index of Crohn's-disease activity. Lancet 1980; i: 514

5 Pranter C A. Clinical and laboratory parameters in Crohn's disease: relation to disease activity, morphology and extent. Ital Gastroenterol 1981; 13: 24-7.

6 Andrè C, Descos L, Landais P, Fermanian J. Assessment of appropriate laboratory measurements to supplement the Crohn's disease activity index. Gut 1981;22:571-4

7 Brignola C, Campieri M, Bazzocchi G, Farruggia P, Tragnone A, Lanfranchi GA. A laboratory index for predicting relapse in asymptomatic patients with Crohn's disease. Gastroenterology 1986; 91 : 1490-4.

8 Meyers S, Walke A, Field STP, Feuer EJ, Johnson JW, Janowitz HD. Fecal alpha-1-antitrypsin measurement: an indicator of Crohn's disease activity. Gastroenterology 1985; 89: 13-8.

9 De Dombal FT, Softley A. IOIBD report 1: observer variation in calculating indices of severity and activity in Crohn' in calculating indices of sever

10 Mary JY, Modigliani R. Development and validation of an endoscopic index of the severity for Crohn's disease: prospective multicentre study. Gut 1989; 30: 983-9.

11 Modigliani R, Mary JY, Simon JF, Cortot A, Soule JC, Gendre $\mathrm{JP}$, et al. Clinical, biological, and endoscopic of attacks of Crohn's disease. Gastroenterology 1990; 98: 811-8.

12 Stein DT, Gray GM, Gregory PB, Anderson M, Goodwin DA McDougall RJ. Location and activity of ulcerative and Crohn's colitis by indium 111 leukocyte scan. Gastroenterology 1983; 84: 388-93.

13 Saverymuttu SH, Camilleri M, Rees H, Lavender JP, Hodgson HJF, Chadwick VS. Indium 111-granulocyte scanning in the assessment of disease extent and disease scanning in the assessment of disease extent and disease
activity in inflammatory bowel disease. A comparison with activity in inflammatory bowel disease. A comparison with colonoscopy, histology and fecal indium-1

14 Saverymuttu SH, Peters AM, Lavender JP, Pepys MB Hodgson HJ, Chadwick VS. Quantitative fecal indium 11 labelled leucocyte excretion in the assessment of disease in Crohn's disease. Gastroenterology 1983; 85: 1333-9.

15 Keshavarzian A, Price YE, Peters AM, Lavender JP, Wrigh NA, Hodgson HJF. Specificity of indium-111 granulocyte scanning and fecal excretion measurement in inflammatory bowel disease - An autoradiographic study. Dig Dis Sci 1985 ; 30: $1156-60$.

16 Scholmerich J, Schmidt E, Schumichen C, Billman P, Schmid $\mathrm{H}$, Gerok W. Scintigraphic assessment of bowel involvement and disease activity in Crohn's disease using technetium $99 \mathrm{~m}$-hexamethyl propylene amine oxime as leukocyte label. Gastroenterology 1988; 95: 1287-93.
17 Ferrante A, Thong YH. Optimal conditions for simultaneous purification of mononuclear and polymorphonuclear leucopurification of mononuclear and polymorphonuclear leucocytes from human peripheral blood by the Hypa

18 Mc Afee JG, Samin A. In-111 labeled leukocytes: a review of problems in image interpretation. Radiology 1985; 155 221-9.

19 Becker W, Fischbach W, Deiners C, Borner W. Three-phase white blood cell scan: diagnostic validity in abdomina inflammatory diseases. F Nucl Med 1986; 27: 1109-15.

20 Crama-Bohbouth G, Pena AS, Biemond I, Verspaget HW, Blok D, Arndt JW, et al. Are activity indices helpful in assessing active intestinal inflammation in Crohn's disease? Gut 1989; 30: 1236-40.

21 Peters AM, Danpure HJ, Osman S, Hawker RJ, Henderson BL, Hodgson HJ, et al. Clinical experience with $99 \mathrm{Tc}$ hexamethylpropylene-amineoxime for labelling leucocytes and imaging inflammation. Lancet 1986; ii: $946-9$.

22 Mc Afee JG, Subramanian G Gagne G, Schneider RF, Zapf Longo C. Tc-99m-HM-PAO for leukocyte labelling-experiLongo C. Tc-99m-HM-PAO for leukocyte labelling-experimental comparison with

23 Gibson P, Lichtenstein M, Salehi N, Hebbard G, Andrews J Value of positive technetium-99m leucocyte scans in predicting intestinal inflammation. Gut 1991; 32: 1502-7.

24 Meignan M, Wirquin E. Lymphocyte radiolabeling: a challenge to their survival. 7 Nucl Med 1987; 28: 1228-9.

25 Middleton SI, Wraight EP, Hunter JO. Comparative study of 99mTc HMPAO and indium 111 tropolone leucocyte scintigraphy in inflammatory disease. Gut 1991; 32: A582.

26 Lantto E, Jarvi K, Krekela I, Lantto T, Taavitsainen M, Vedenkangas H, et al. Technetium-99m hexamethyl propylene amine oxime leucocytes in the assessment of disease pylene amine oxime leucocytes in the assessment of disease activity in inflam

27 Crama-Bohbouth GE, Pena AS, Arndt JW, Tjou RTO, Thaw $\mathrm{A}$, Verspaget $\mathrm{HW}$, et al. Value of indium-111 tropolonate autologous granulocyte scintigraphy in the assessment of inflammatory bowel disease. Scand f Gastroenterol 1990; 25 : 93-8

28 Carrol B, Silverman PM, Goodwin DA, McDougall IR Ultrasonography and indium 111 white blood cell scanning for the detection of intra abdominal abscesses. Radiology 1981; 140: 155-60.

29 Seabold JE, Wilson DG, Lieberman LM, Boyd CM Unsuspected extra-abdominal sites of infection: scintigraphic detection with indium-111-labeled leukocytes. Radiology 1984; 151: 213-7.

30 Lantto EH. Leucocytes labelled with $99 \mathrm{mTc}$-HMPAO in the detection of abdominal abscesses. Eur $\mathcal{F}$ Surg 1991; 157: 469-72.

31 Malchow H, Ewe K, Brandes JW, Goebell H, Ehms H, Sommer $\mathrm{H}$, et al. European cooperative Crohn's disease study (ECCDS): results of drug treatment. Gastroenterology 1984; 86: 249-66.

32 Olaison G, Sjodahl R, Tagesson C. Glucocorticoid treatment in ileal Crohn's disease: relief of symptoms but not of endoscopically viewed inflammation. Gut 1990; 31: 325-8.

33 Saverymuttu SH. Clinical remission in Crohn's disease Assessment using faecal 111 In granulocyte excretion. Digestion 1986; 33: 74-9.

34 Segarra I, Roca M, Baliellas C, Vilar L, Ricart Y, Mora J, et al. Granulocyte-specific monoclonal antibody technetium-99mBW $250 / 183$ and indium- 111 oxine-labelled leucocyte scintigraphy in inflammatory bowel disease. Eurf Nucl Med 1991; graphy in inflis-9.

35 Becker WS, Saptogino A, Wolf FG. The single late $99 \mathrm{Tcm}$ granulocyte antibody scan in inflammatory diseases. Nucl Med Commun 1992; 13: 186-92. 